\title{
STUDY OF THE IMPACT OF THE TOPOLOGY OF THE SHUNT ACTIVE FILTER ON THE NEUTRAL CURRENT
}

\author{
Mahmoud HABAB, Chellali BENACHAIBA, Cherif BENOUDJAFER \\ Department of Electrical Engineering, Faculty of Electrical Engineering,Universtity of Bechar, BP 417, Bechar 08000, Algeria, \\ e-mail: hababmahmoud@yahoo.fr
}

\begin{abstract}
The shunt active filter is a new solution to improve the power quality. It is able to compensate the current disturbances as well as the reactive power. This paper shows the impact of the neutral current compensation on the two different topologies, according to the obtained results, the configuration with four arms is more preferment than the classical topology which uses the inverter with three arms.
\end{abstract}

Keywords: Unbalanced electric, neutral current, active filter, compensation

\section{INTRODUCTION}

The three phase's network, with four wires for electrical energy distribution, is generally used to supply residential, offices.... Most of the applications connected to four wires system are single-phases dispositive that consume a current containing many harmonics.

In addition, the use of single-phases loads cause many other undesirable effects, such as unbalanced phase current causing the presence of a neutral current flowing through the fourth wire system. Shunt active filters provide an effective solution to improve the power quality.

\section{DESCRIPTION OF TOPOLOGIES}

The shunt active filter with four wires has the objective to delete the harmonic component of the current, compensate the neutral current, balance the source current and the correct of the power factor:

- The shunt active filter with four wires of three arms is based on conventional converter with three arms an six controllable switches, whom the neutral wire is directly connected to the middle of the DC connection (Fig.1) [1].

- The shunt active filter with four wires of four arms is based on conventional inverter with four arms and height controllable switches; thereby the neutral wire is connected through a connection filter in the fourth arm of the converter [2].

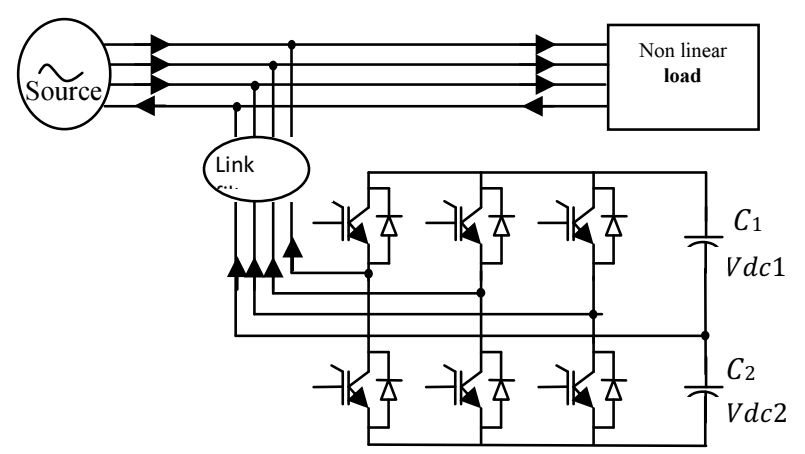

Fig. 1 S.A.F. with three arms

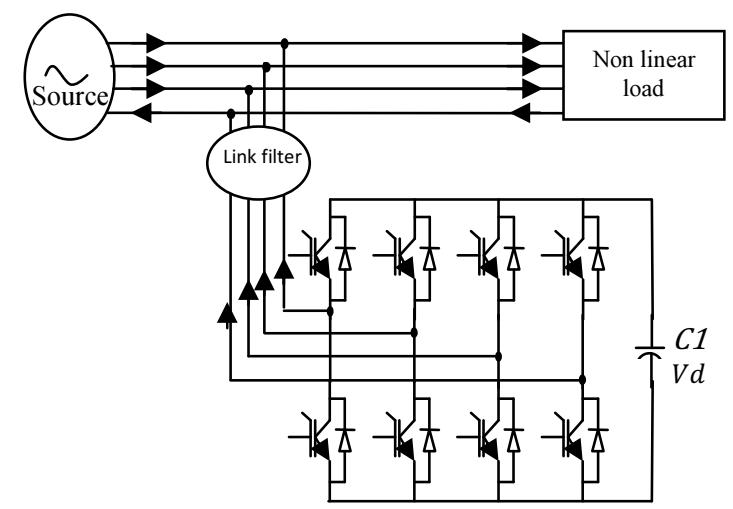

Fig. 2 S.A.F. with four arms

\section{UNBALANCED SYSTEM}

In this particular case, the converter is designed not to a balanced load but to an unbalanced one [3].

\subsection{Definition of unbalance}

There are different approaches to define the unbalanced loads. One of these approaches is based on the difference between the largest amplitude and the smallest one, of the three phases.

UnBal $\%=100 \times \frac{\text { Max Amplitude }- \text { Low Amplitude }}{\sum \text { three amplitudes }}$

where: UnBal \% - the unbalance in a three phase system

Another approach is based on the definition of a sequential representation. According to IEC defines the unbalance in a three phase system as the ratio between the RMS values of the negative sequence or the zero sequence vis-a-vis to the positive sequence.

UnBal $\%=100 \times \frac{\text { Negative sequence component }}{\text { Positive sequence component }}$ 
And

UnBal $\%=100 \times \frac{\text { Zero sequence component }}{\text { Positive sequence component }}$

\subsection{Creation of the neutral connexion}

In a three-phases balanced system with three arms, the sum of the three phase currents equal to zero and also for the voltage. For the unbalanced load system, the voltage of the neutral line will become unbalanced [1].

\subsubsection{Passive methods with transformer $\Delta / Y$}

Transformer $\Delta / \mathrm{Y}$ is designed to trap the zero sequence. The first part ( $\Delta$ windings) are connected with the inverter while the second part (Y windings) are connected to the load. Zero-sequence current caused by the load is trapped in the $(\Delta)$ windings. Another way to provide passive connection is to use a neutral transformer zigzag, which also balances the load to a certain extent.

\subsubsection{Passive methods with division of the link condenser}

In this topology, the division of the DC link capacity where the neutral point is connected in the midway between the two capacitors (Fig. 1), there are two problems with this approach:

- The neutral point will be fixed in the middle of the DC link, which will cause a misuse of continuous voltage.

- Huge increase in capacity is required to maintain the ripple voltage at a reasonable level.

\subsubsection{Active method}

The active method consists in connecting the neutral connection of the load at the midpoint of the fourth arm, the PWM control converter with four arms can handle the neutral current caused by unbalanced load (Fig. 2), the advantages of this method are :

- The possibility of using a high voltage of the DC link.

- No bulky transformers.

- Capacitor used in this method, is a smaller capacity therefore, the cost is low.

\section{CONTROL CIRCUIT}

The application of the synchronous reference frame (Synchronous Reference Frame, SRF) is based on the extraction of the current harmonic of the load, injecting in the opposite sense to obtain sinusoidal source current and finally injecting inverse current into the fourth arm to achieve a zero neutral current (Fig. 3).

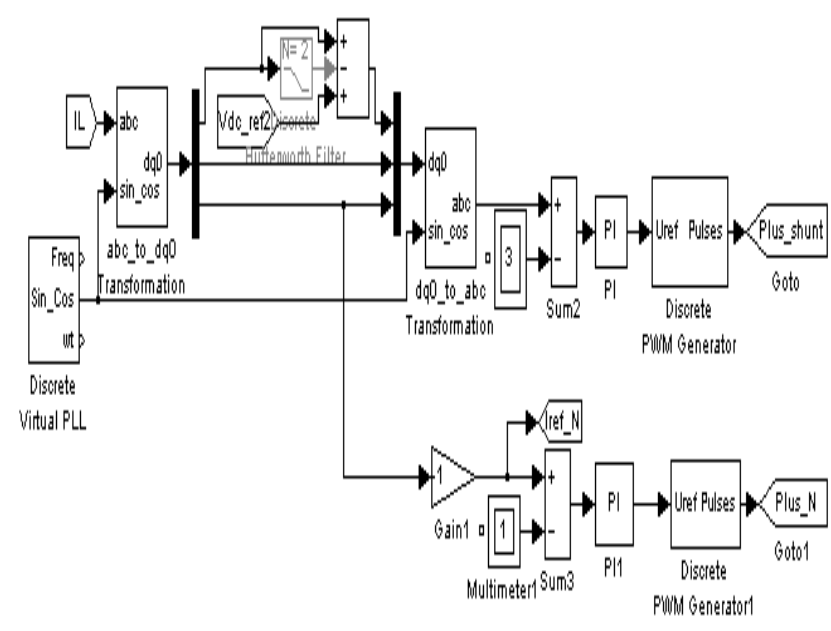

Fig. 3 Control circuit of S.A.F

\subsection{Study Shunt active filter}

For the determination of the parameters of the PI controller to adjust the control loops shunt were used methods of imposed phase for the determination of controller parameters DC bus, using the pole placement method [4],[5].

The control scheme represented as follows [6].

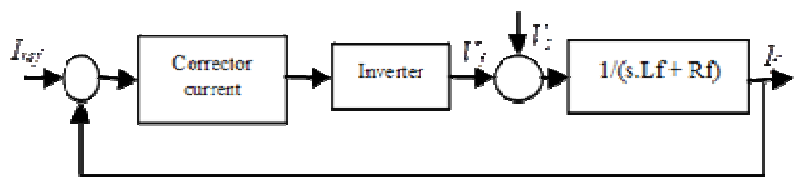

Fig. 4 Control Loop shunt filter

Following a gap between $\mathrm{V}_{\mathrm{dc}}$ and $\mathrm{V}_{\mathrm{dcré}}$ as shown in Figure 5, the power output of the controller is added to the active power fluctuation and gives rise to a fundamental active current and voltage correcting [7].

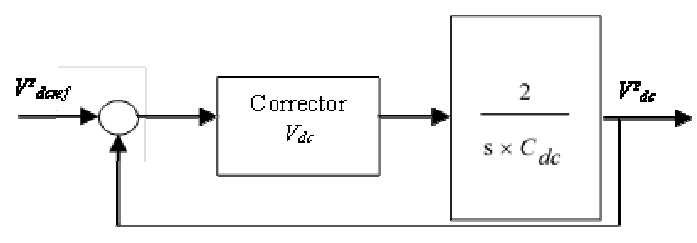

Fig. 5 Control loop of the DC bus of the inverter

\section{RESULTS}

In this study we present a comparison between a shunt active filter with three arms connected to the neutral wire which are connected to the midpoint of the two capacitors (Fig. 6.), and another shunt active filter with four arms which is connected to the fourth arm (Fig. 7.). The SAF model parameters are shown in the following Table 1. 
Table 1 SAF parameters

\begin{tabular}{|l|c|}
\hline Supply phase voltage $U$ & $220 \mathrm{~V}$ \\
\hline Supply frequency $f_{s}$ & $50 \mathrm{~Hz}$ \\
\hline Sample time $T s$ & $9.9 \mu \mathrm{s}$ \\
\hline Filter inductor $L_{f}$ & $2.2 \mathrm{mH}$ \\
\hline Dc link capacitor $C_{f}$ & $8.7 \mathrm{mF}$ \\
\hline Dc link voltage & $735.6 \mathrm{~V}$ \\
\hline $\begin{array}{l}\text { Active power of the } \\
\text { nonlinear load }\end{array}$ & $8 \mathrm{KW}$ \\
\hline $\begin{array}{l}\text { Reactive power of the } \\
\text { nonlinear load }\end{array}$ & $\begin{array}{c}16 \mathrm{KW}, 80 \mathrm{KW} \\
\text { and } 8 \mathrm{KW}\end{array}$ \\
\hline $\begin{array}{l}\text { Active power } \\
\text { unbalanced load }\end{array}$ & $\begin{array}{c}500 \mathrm{Var}, 150 \mathrm{Var} \\
\text { and } 500 \mathrm{Var}\end{array}$ \\
\hline $\begin{array}{l}\text { Reactive power } \\
\text { unbalanced load }\end{array}$ & \\
\hline
\end{tabular}

The shunt active filter with three arms is represented in the fig. 6 .

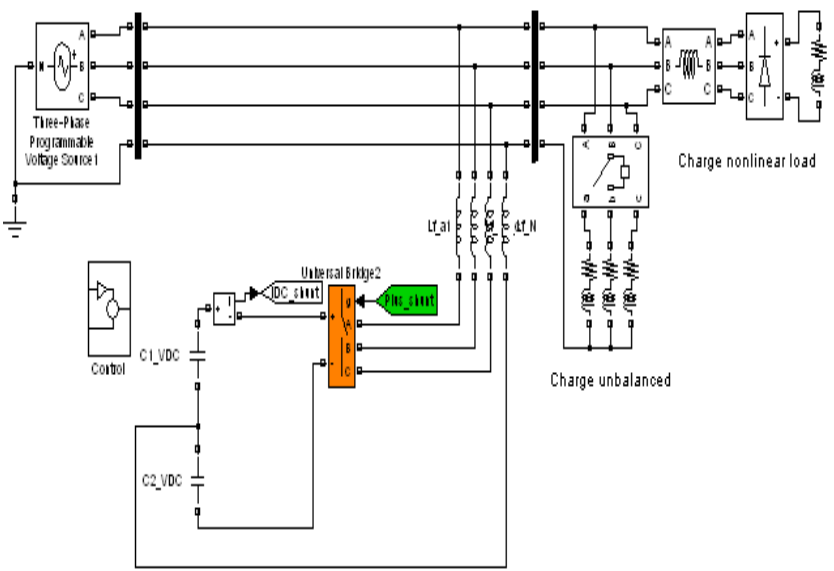

Fig. 6 Simulation model of SAF with three arms

And the Shunt active filter with four arms is represented in the fig. 7 .

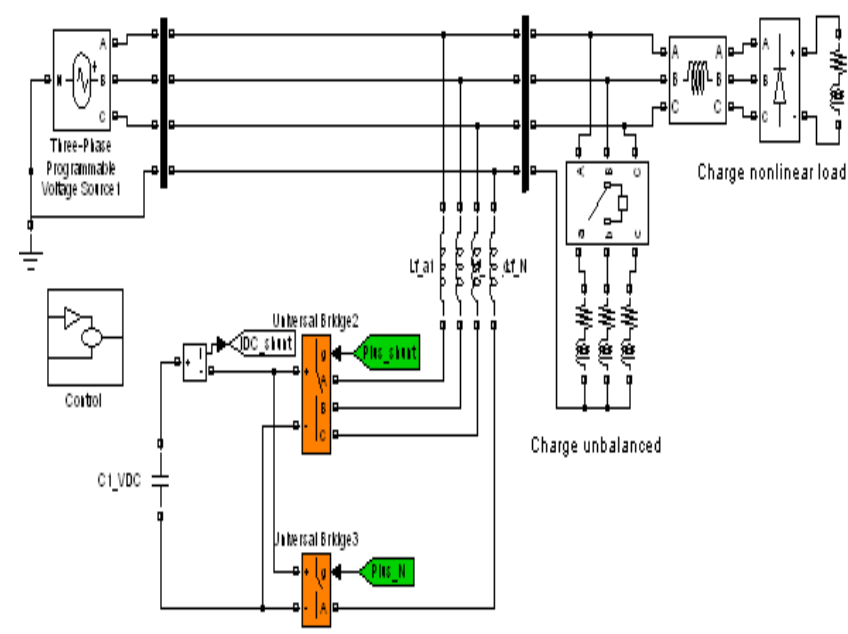

Fig. 7 Simulation model of S.AF with four arms

\subsection{S.A.F with three arms}

a) Load current

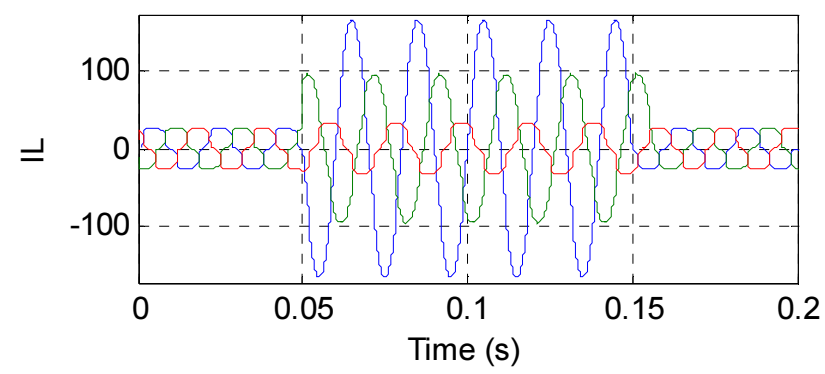

b) Injected current

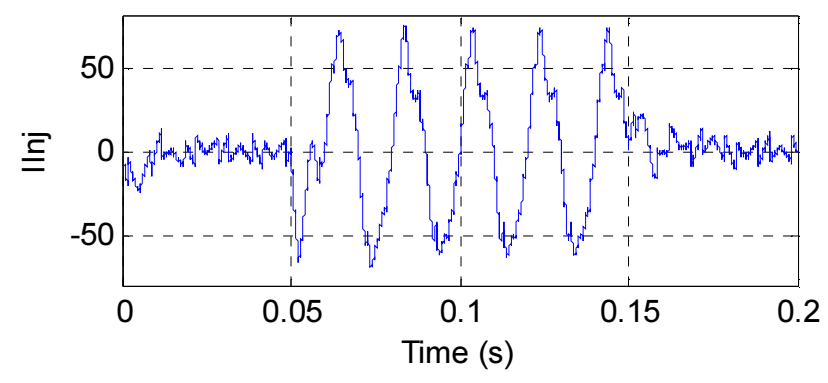

c) Source current

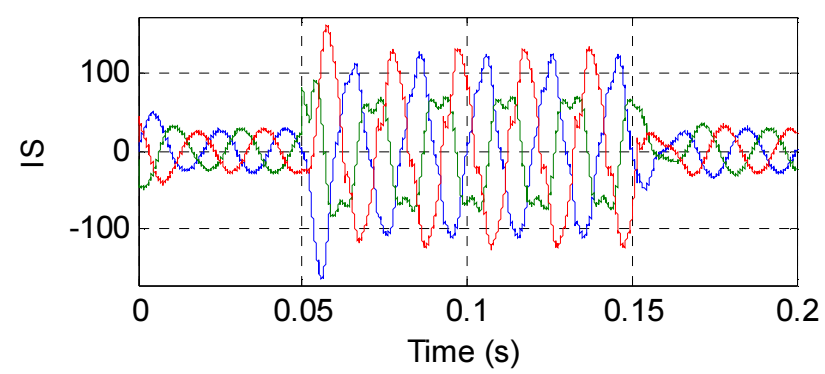

d) Dc bus $V_{d c}$

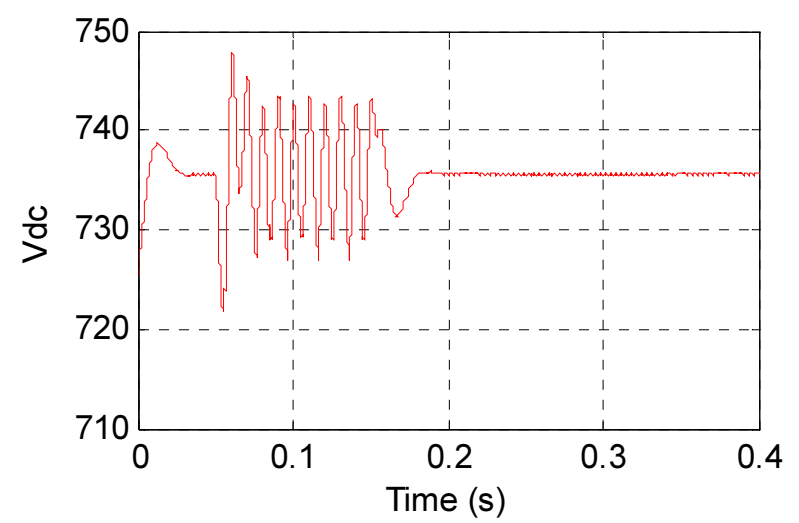

e) Neutral current of the load

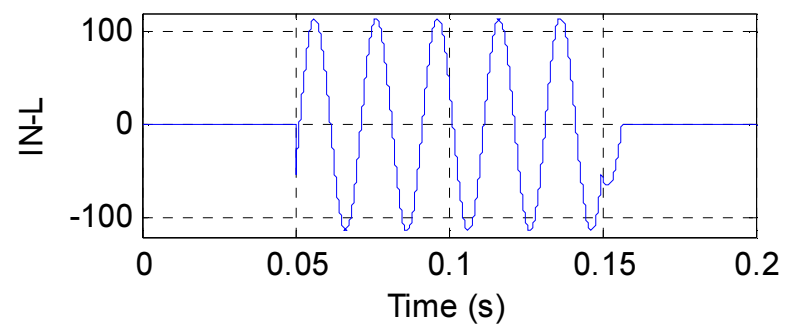


f) Neutral current of the source



Fig. 8 Simulation results of S.A.F with three arms

\subsection{S.A.F with four arms}

a) Load current

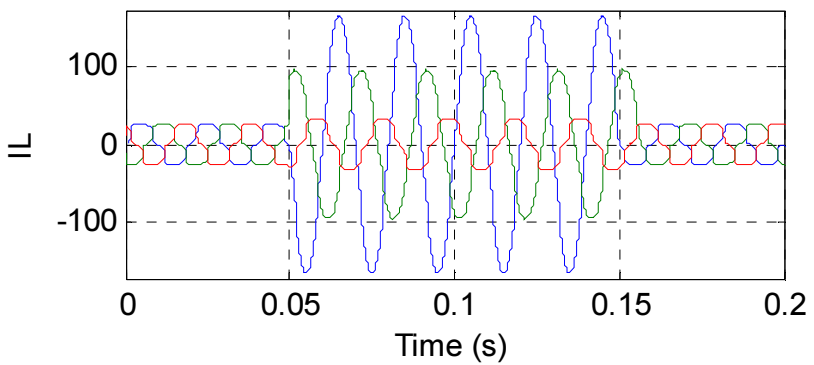

b) Injected current

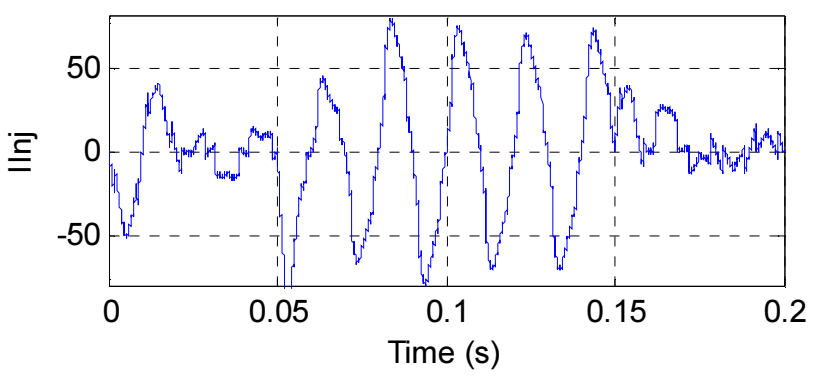

c) Source current

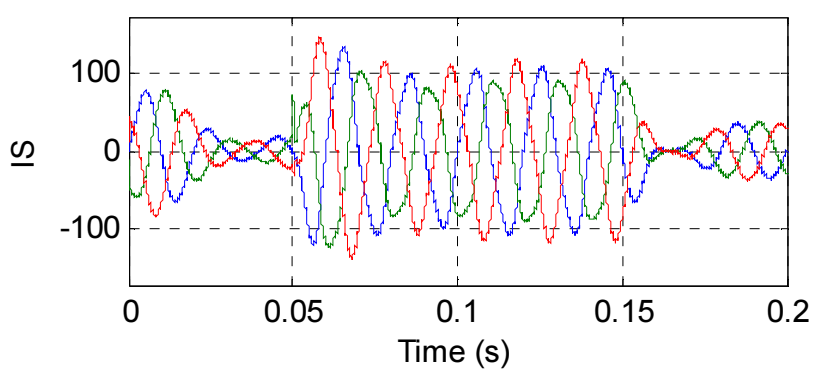

d) Dc bus $V_{d c}$

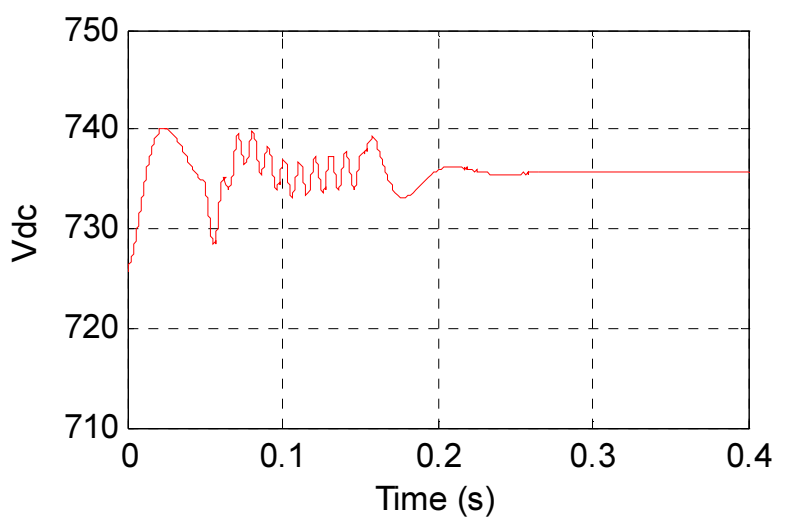

e) Neutral current of the load

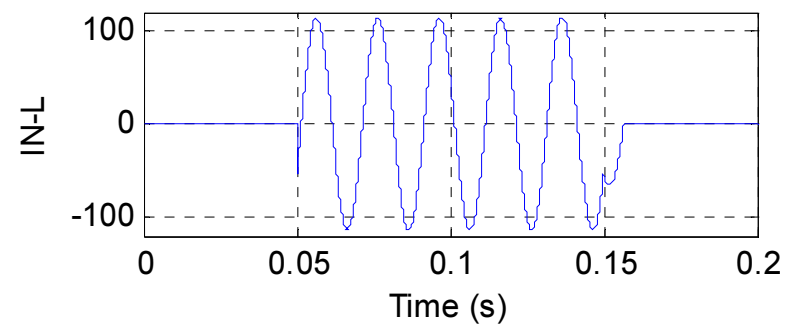

f) Neutral current of the source

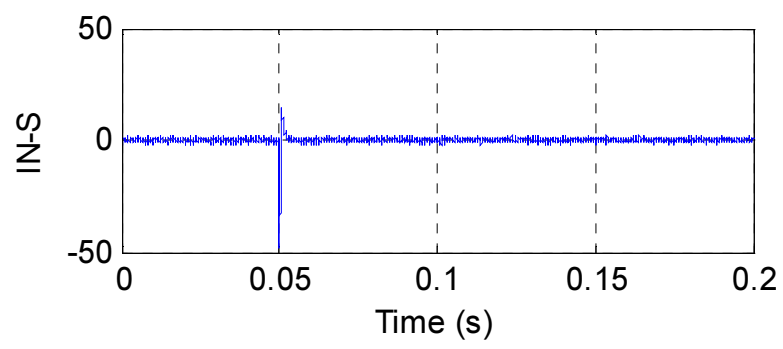

Fig. 9 Simulation results of S.A.F with four arms

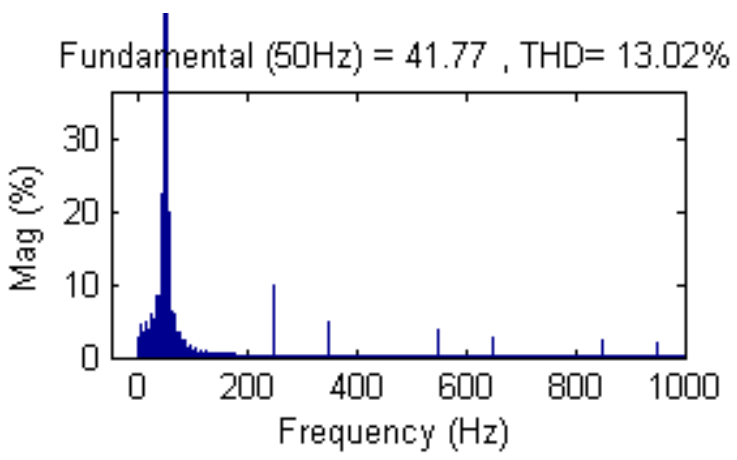

Fig. 10 THD of load current

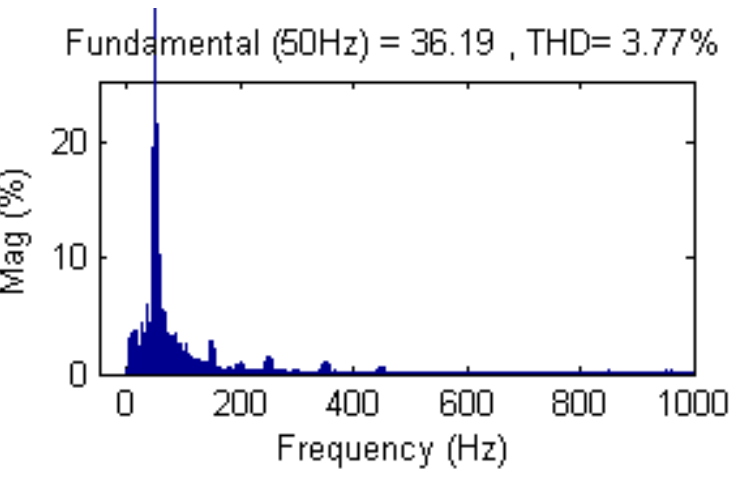

Fig. 11 THD of current source (S.A.F with tree arms)



Fig. 12 THD of current source (S.A.F with four arms) 
For the simulation, the three-phase voltages at the coupling point are assumed sinusoidal and balanced. The nonlinear load is constituted by a three-phase rectifier diode bridge feeding a load $(\mathrm{R}, \mathrm{L})$, as there are three single-phase auxiliary loads for generating the current unbalance for a time definite $(0.05 \mathrm{~s}$ to $0.15 \mathrm{~s})$ (Fig. 6, Fig.7).

Figure 10 (a) shows current source by S.A.F with three arms is poorly compensated the phenomenon of unbalanced, Figure 8 (f) shows the three-arm S.A.F the neutral current decreases from $110 \mathrm{~A}$ to $40 \mathrm{~A}$. Figure 9 (f) shows S.A.F with four arms that the neutral current decreases from $110 \mathrm{~A}$ to $1.5 \mathrm{~A}$.

Figures 8 (d) and 9 (d) shows the lure of the DC bus voltage $V d c$.

The topology of S.A.F with tree arms reduced the THD of current source from $13.02 \%$ to $3.77 \%$ (Fig. 11), while the THD of current source is measured by a four arms S.A.F is corrected to $2.79 \%$ (Fig. 12).

\section{CONCLUSIONS}

The work presented here, is a part of the researches for new solutions to improve the quality of the electrical energy into the grid.

The obtained results show that the shunt active filter simulation with four arms are better than the three arms . When the neutral conductor is connected to the fourth arm ,this gives us, suitable results compared to the neutral wire which is connected to the midpoint of the two condensers.

\section{REFERENCES}

[1] ABDELKHALEK, O.: Study and simulation of a UPQC for eliminations of the harmonics in real time in the electrical supply network. Doctorate thesis, February 21, 2010.

[2] BENACHAIBA, C.: Contribution à l'Elimination des Harmoniques Par le Filtre Actif en Temps Réel dans les Réseaux Electriques. Doctorate thesis, June 29, 2005.

[3] MOHAMAD, A. E.: Contribution à l'étude des compensateurs actifs des réseaux électriques basse tension. Doctorate thesis, September 12, 2002.

[4] HANANE, K.: Application d'un filtre actif série au contrôle de la tension d'un réseau basse tension, Thesis magister in electrical engineering, February 08, 2006.

[5] SIMONE, B. - PAOLO, M.: Digital control in power electronics, Morgan \& Claypool, Synthesis series 2006.

[6] MOURICE, R. - JEAN, L. F.: Cours d'automatique (asservissement-régulation) commande analogique, Tome 2, EYROLLES 1990-1992, Chihab, 1994.

[7] Norm's IEEE Std 519-1992.: IEEE recommended practices and requirements for harmonic control in electrical power systems, April 12, 1993, pp. 15 - 99.
[8] SENTHILKUMAR, A. - AJAY, D. V.: Investigations on Dynamic Performance of Hybrid Shunt Active Power Filter Strategy for Power Quality Enhancement Using PI Controller and Neural Learning Algorithm for Three Phase Three Wire Distribution System, Journal of Electrical Engineering, vol. 12, 2012, edition 4.

[9] IEEE Std 519-1992.: IEEE recommended practices and requirements for harmonic control in electrical power systems, April 12, 1993.

[10] LOTT, C.: Filtrage Actif Parallèle des Harmoniques de courant sur des Réseaux Industriels: Etude Théorique et Réalisation d'une maquette à GTO. Doctorate thesis, institut National Polytechnique de Lorraine, Nancy Oct. 17, 1995.

[11] SANKAR, S.: Power quality analysis of magnitude in unbalanced system, Journal of Electrical Engineering, vol. 11, 2011, Edition: 2.

[12] YASH, P. - SWARUP, A. - BHIM, S.: A novel Control strategy of UPQC for Power Quality Improvement, Journal of Electrical Engineering, vol. 11, 2011, edition: 2 .

[13] BRYANT, N. : Generalized study and Ordering of the Active Filter Total or Selective ParallelCompensation of the Harmonics in Balanced and Unbalanced Mode. Doctorate thesis, University of Nantes 1999.

[14] DEHINI, R. - BASSOU, A. - FERDI, B.: Harmonic current compensation in active power filter based on adaptive neural network, Journal of Electrical Engineering, vol. 11, 2011, edition: 1.

Received August 15, 2013, accepted February 14, 2014

\section{BIOGRAPHIES}

Mahmoud HABAB was born on 16.03.1971. In 2010 he graduated (MSc) in electotechnic from University of Bechar (Algeria) and in 1994 Engineer in Electrotechnic from University of Tiaret (Algeria). His scientific research is the field of wind energy and electric energy quality (FACT).

Chellali Benachaiba obtained Doctorate in Electrical Engineering from University of Science and Technology of Oran (Algeria) in 2005, Magister in Energetic Physics from University of Bechar (Algeria) in 1996 and a Diploma Engineer in Electrification from University of Boumerdes (Algeria) in 1987.

Cherif Benoudjafer, Assistant professor, in 2009, Magister in electotechnic from University of Bechar (Algeria) and in 2006 Engineer in Electrotechnic from University of Bechar. Leads research on the field of ind energy and electric energy quality. 